\title{
Dopamine Replacement Therapy Reverses Abnormal Synchronization of Pallidal Neurons in the 1-Methyl-4-Phenyl- 1,2,3,6-Tetrahydropyridine Primate Model of Parkinsonism
}

\author{
Gali Heimer, Izhar Bar-Gad, Joshua A. Goldberg, and Hagai Bergman \\ Department of Physiology, the Interdisciplinary Center for Neural Computation and the Eric Roland Center for \\ Neurodegenerative Diseases, The Hebrew University-Hadassah Medical School, Jerusalem, 91120 Israel
}

Previous physiological studies have revealed changes in firing rates and synchronization of pallidal neurons in the 1-methyl4-phenyl-1,2,3,6-tetrahydropyridine (MPTP) primate model of Parkinson's disease. Several primate and human studies have demonstrated that dopamine replacement therapy (DRT) reverses the changes in the pallidal firing rates; however, the effects of DRT on pallidal synchronization have never been explored. To do so, we recorded the simultaneous activity of pallidal neurons of a vervet monkey before and after induction of severe parkinsonism by systemic MPTP treatment. We subsequently recorded the pallidal activity before and after daily administration of oral DRT. We extended the time scale of our correlation studies to $\pm 5 \mathrm{sec}$ to allow detection of longduration synchronized neuronal activity. After MPTP treatment, firing rates decreased in the external segment of the globus

Many previous studies have reported changes in the activity of globus pallidus (GP) neurons in 1-methyl-4-phenyl-1,2,3,6tetrahydropyridine (MPTP)-treated monkeys compared with healthy ones. Firing rates of the internal segment of the GP $\left(\mathrm{GP}_{\mathrm{i}}\right)$ cells are increased, whereas the external segment of the GP $\left(\mathrm{GP}_{\mathrm{e}}\right)$ cells display decreased firing rates (Miller and DeLong, 1987; Filion and Tremblay, 1991). Single-electrode recordings performed on human parkinsonian patients during surgical interventions designed to relieve parkinsonian symptoms indicate trends in firing rates similar to those found in primates (Hutchison et al., 1994; Merello et al., 1999).

Changes in firing synchronization have also been reported in parkinsonian subjects. Whereas in normal monkeys, activity within the basal ganglia is mostly independent, synchronous oscillations are found in MPTP monkeys (Nini et al., 1995; Raz et al., 2000) and in human parkinsonian patients (Hurtado et al., 1999; Levy et al., 2000).

Many electrophysiological studies have indicated that the

Received March 25, 2002; revised June 24, 2002; accepted July 1, 2002.

This Center of Excellence (8006/00) research was supported by the Israel Science Foundation. It was also supported by the United States-Israel Binational Science Foundation, the German-Israel Binational Foundation, and the Joint GermanIsrael Research Program. V. Sharkansky provided technical support. We thank G. Goelman (Hadassah Hospital, Jerusalem) for assistance with the magnetic resonance imaging and S. Haber (University of Rochester) for help with the histological studies. We thank E. Vaadia and S. Hocherman for critical reading.

Correspondence should be addressed to Gali Heimer, Department of Physiology, The Hebrew University-Hadassah Medical School, P.O. Box 12272, Jerusalem, 91120 Israel. E-mail: galih@md.huji.ac.il.

Copyright $\odot 2002$ Society for Neuroscience $0270-6474 / 02 / 227850-06 \$ 15.00 / 0$ pallidus $\left(\mathrm{GP}_{\mathrm{e}}\right)$ and increased in the internal segment $\left(\mathrm{GP}_{\mathrm{i}}\right)$. A reversal of these rate changes occurred during the "on" periods of DRT. The percentage of correlated pairs increased from $16.7 \%$ in the normal state to $46.9 \%$ after MPTP treatment and was restored to nearly normal values (25\% correlated pairs) under the influence of DRT. These changes in rate and correlation were observed at both the population level and at the level of units recorded continuously before, during, and after the clinical transition from "off" to "on" periods. We conclude that changes in both pallidal discharge rates and synchronization are correlated with the clinical manifestations of parkinsonism and its pharmacological treatment.

Key words: Parkinson's disease; globus pallidus; basal ganglia; monkeys; cross-correlations; L-3,4-dihydroxyphenylalanine

changes of pallidal firing rates are reversed after administration of dopamine replacement therapy (DRT) in humans (Hutchinson et al., 1997; Merello et al., 1999; Levy et al., 2001) and primates (Filion et al., 1991; Papa et al., 1999) (but see Boraud et al., 1998). However, all of these studies were confined to the activity of single neurons. In this study, we used multiple electrode recording to examine the effect of DRT on neuronal synchronization in the two segments of the pallidum.

\section{MATERIALS AND METHODS}

Animals and behavioral paradigm. A vervet monkey (Cercopithecus aethiops aethiops; female; weight, $3.8 \mathrm{~kg}$ ) was trained to perform a buttonpressing task. The monkey's health was monitored by a veterinarian, and its fluid consumption, diet, and weight were observed daily. All procedures were in accordance with the National Institutes of Health Guide for the Care and Use of Laboratory Animals (1996) and with the Hebrew University guidelines for the use and care of laboratory animals in research and were approved and supervised by the Institutional Animal Care and Use Committee.

Surgical procedures. After training, an $18 \mathrm{~mm}$ Cilux recording chamber was attached to the skull over a trephine hole to allow access to the GP. The recording chamber was tilted $50^{\circ}$ laterally in the coronal plan, with its center targeted at stereotaxic coordinates A12, H1, and L9 (Contreras et al., 1981). The coordinates of the chamber were adjusted and subsequently verified with magnetic resonance imaging (Biospec Bruker 4.7 tesla animal system, fast spin echo sequence; effective echo time, 80 msec; repetition time, $2.5 \mathrm{sec}$; 13 coronal slices $2 \mathrm{~mm}$ wide). All surgical and magnetic resonance imaging procedures were performed under general anesthesia (induced and maintained by ketamine hydrochloride $13 \mathrm{mg} / \mathrm{kg}$ and xylazine $0.5 \mathrm{mg} / \mathrm{kg}$ i.m.).

Recording procedures and data collection. During recording sessions, the monkey's head was immobilized, and eight glass-coated tungsten microelectrodes (impedance $0.3-1.2 \mathrm{M} \Omega$ at $1000 \mathrm{~Hz}$ ), confined within a 
cylindrical guide (1.65 $\mathrm{mm}$ inner diameter), were advanced separately (EPS; Alpha-Omega Engineering, Nazareth, Israel) into the GP. The penetrations covered most of the pallidal volume. The recording boundaries extended from 2 to $-4 \mathrm{~mm}$ anterior and from 4 to $7 \mathrm{~mm}$ lateral to the center of the chamber.

Each electrode signal was amplified with a gain of 5000-20,000 and bandpass filtered with a $300-6000 \mathrm{~Hz}$ four-pole Butterworth filter (MCP+; Alpha-Omega Engineering, Nazareth, Israel). This electrical activity was sorted and classified on-line using a template-matching algorithm (MSD; Alpha-Omega Engineering). The sampling rate of spike detection pulses and behavioral events was $12 \mathrm{kHz}$ (AlphaMap, Alpha-Omega Engineering).

Cells were selected for recording only as a function of their isolation quality and optimal signal-to-noise ratio. Only stable and well isolated (as judged by stable spike waveforms and stable firing rates) units were included in this study (minimum stable recording time of $4 \mathrm{~min}$ ). The average stable recording time was $25 \pm 10.6$ min (mean $\pm \mathrm{SD}$ ). The classification of each recorded cell to the external and internal pallidum was determined according to several criteria: the depth of the electrode (depths from the first pallidal unit of $\mathrm{GP}_{\mathrm{e}}$ and $\mathrm{GP}_{\mathrm{i}}$ cells included in the study were $0.5 \pm 0.4$ and $2.5 \pm 0.8 \mathrm{~mm}$, mean $\pm \mathrm{SD}$, respectively); other anatomical structures identified along the electrode trajectory; the firing pattern of the cell (which served as a criterion only in the normal state); and shape of the cell spikes. If the subclassification into $\mathrm{GP}_{\mathrm{e}}$ and $\mathrm{GP}_{\mathrm{i}}$ was in doubt, the units were classified as GP.

MPTP and DRT. Parkinsonism was induced by five intramuscular injections of $0.4 \mathrm{mg} / \mathrm{kg}$ of the MPTP-HCl neurotoxin (Aldrich, Milwaukee, WI) over a period of $4 \mathrm{~d}$. The monkey developed severe parkinsonism $5 \mathrm{~d}$ after initiation of MPTP treatment, and recordings were resumed $4 \mathrm{~d}$ after the last injection. After $14 \mathrm{~d}$ of recordings in the parkinsonian state, we initiated daily DRT with starting doses of $0.5 \times 25 / 250 \mathrm{mg}$ of Dopicar [L-3,4-dihydroxyphenylalanine (L-DOPA) and carbidopa; MSD, Netherlands] in the morning and $5 \mathrm{mg}$ of Parlodel (bromocryptine; Sandoz, Basel, Switzerland) divided equally between morning and evening. The drugs were administered orally as crushed powder dissolved in liquid, and the doses were slowly increased and adjusted to achieve optimal clinical response. Maximal doses attained were $1.5 \times 25 / 250 \mathrm{mg}$ of Dopicar with $2.5 \mathrm{mg}$ of Parlodel in the morning and $1 \times 25 / 250 \mathrm{mg}$ of Dopicar with $2.5 \mathrm{mg}$ of Parlodel in the evening. The clinical state was assessed daily in the home cage using a modified primate parkinsonism and dyskinesia scale (Imbert et al., 2000). During the recordings, DRT"off" periods were defined as the periods before the morning dose (at least $12 \mathrm{hr}$ after the evening dose). The clinical definition of the "off-on" transition was based on observation of limbs and tail movements, resumption of task performance, or appearance of involuntary dyskinetic movements (at the stage when these had already developed).

Recordings during the DRT state started $3 \mathrm{~d}$ after onset of treatment (21 d after the last MPTP injection). Each day, we recorded for 10-30 min in the off period. We then administered the medications while keeping the electrodes in position, and subsequently resumed the recordings. In many cases, this protocol allowed for recording of a given unit before, during, and after administration of DRT. In other cases, when units were lost during the oral administration of the drugs, it still enabled us to record the activity of other cells in the immediate vicinity of the cells studied before DRT. Although we recorded the ongoing discharge changes of cells in response to the medication, we included only the stable segments before and after these transients in the analysis. Periods of complete cessation of $\mathrm{GP}_{\mathrm{i}}$ discharge were excluded from the analysis because of the inability to characterize the firing patterns and neuronal synchronization of cells that were virtually inactive.

Data analysis. We performed quantitative analysis of firing rates and correlated activity of the pallidal cells. Statistical tests were accepted as significant at a value of $p<0.001$ unless specified otherwise. The same threshold was applied in the analysis of neural activity for all clinical states.

Only cross-correlograms of pairs recorded by different electrodes were included to avoid possible artifacts caused by a shadowing effect of high-discharge cells recorded from the same electrode (Bar-Gad et al., 2001). The correlograms were calculated for $\pm 5000 \mathrm{msec}$ offset, using 1 msec bins and recording edge correction. We tested the null hypothesis of independent activity (i.e., flat cross-correlogram) by searching either for significant peaks and troughs or for significant periodic oscillations. Baseline firing rate and SD were estimated using the first and last 500 $\mathrm{msec}$ of the $\pm 5000 \mathrm{msec}$ cross-correlogram. A peak or trough was considered significant if its probability (normalized to the total number of bins) was $<0.001$ and it was within an offset of $\pm 250 \mathrm{msec}$ from zero. The significance of the oscillatory phenomena was assessed using the Fourier transform of the cross-correlograms (power spectra). The SD of each power spectrum was calculated over the range of 1-200 Hz. A correlogram was considered to have significant periodic oscillations if the peak in the power spectrum crossed a threshold of $p=0.001$ and was within the range of 3-30 $\mathrm{Hz}$ (Raz et al., 2000).

Histology. After the last recording session (98 d after the last MPTP injection), the monkey was killed with a lethal dose of pentobarbital and perfused through the heart with saline followed by a $4 \%$ paraformaldehyde solution. The brain of the monkey was removed, $50 \mu \mathrm{m}$ serial sections were cut on a freezing microtome, and every 12th section was processed for Nissl or tyrosine hydroxylase immunocytochemistry.

\section{RESULTS}

\section{Clinical states}

The first signs of parkinsonism appeared on the third day of the MPTP treatment, in the form of bradykinesia, flexed posture, and lower limb dystonia. Akinesia and freezing developed on day 4, and tremor and rigidity appeared on day 5. By this day, the monkey had lost the ability to perform the behavioral paradigm and to self-feed. This clinical state of severe parkinsonism remained stable during all days of recording in the L-DOPA-naive MPTP monkey, with an average parkinsonism score of 30.0/36.

DRT commenced $18 \mathrm{~d}$ after the last MPTP injection. The first response to the therapy was observed after the third dose of medication ( $24 \mathrm{hr}$ after initiation of treatment). The latency of on periods varied from day to day between 0.5 and $3 \mathrm{hr}$, and the duration exceeded $2 \mathrm{hr}$. The clinical effects of DRT included an increase in amount and velocity of movements, straightening of posture, and regained ability to self-feed and to partially perform the task. In addition, there was an increase in amplitude and duration of the action tremor (Vidailhet et al., 1999). After 6 weeks of daily DRT, the monkey began to exhibit peak-dose dyskinesia. The average parkinsonian scores in the off and on periods were 31.2/36 (not significantly different from the MPTP L-DOPA-naive state) and 2.9/36, respectively. Postmortem examination revealed an almost complete loss of tyrosine hydroxylase staining throughout the striatum and that the vast majority of dopaminergic neurons of the substantia nigra were lost.

\section{Neuronal firing rates}

After MPTP treatment, firing rates decreased significantly in the $\mathrm{GP}_{\mathrm{e}}$ and increased in the $\mathrm{GP}_{\mathrm{i}}$ cells (Table $1 A$ ). The rate changes in $\mathrm{GP}_{\mathrm{i}}$ were significant only at a value of $p<0.05$, probably because of the smaller number of cells. During DRT-off periods, these changes were augmented in the $\mathrm{GP}_{\mathrm{e}}$ and maintained in the $\mathrm{GP}_{\mathrm{i}}$. The rate changes were reversed in both pallidal segments during the on periods (Table $1 A$, Fig. $1 A$ ).

Stable continuous recordings before and after the clinical influence of DRT were obtained in $29 \mathrm{GP}_{\mathrm{e}}$ and six $\mathrm{GP}_{\mathrm{i}}$ cells (Fig. 2). The average firing rate after DRT in the continuously recorded $\mathrm{GP}_{\mathrm{e}}$ cells increased by a factor of 2.8 (44.7 spikes/sec). Of these $\mathrm{GP}_{\mathrm{e}}$ cells, $26(89.7 \%)$ increased their firing rate significantly $(p<$ 0.005 , Student's $t$ test), whereas only two cells $(6.9 \%)$ decreased their firing rate significantly in the on period. The average firing rate after DRT in the continuously recorded $\mathrm{GP}_{\mathrm{i}}$ cells decreased by a factor of 2.4 (27 spikes/sec). Among these $\mathrm{GP}_{\mathrm{i}}$ cells, five $(83.3 \%)$ decreased their firing rate significantly $(p<0.005$, Student's $t$ test), and the remaining one did not change its firing rate significantly in the on period.

\section{Neuronal synchronization}

While most of the pallidal pairs were uncorrelated in the normal state, there was a significant increase in the neuronal correlation 
Table 1. Neuronal firing rates and correlation in the pallidum

\begin{tabular}{|c|c|c|c|c|c|}
\hline & & Normal & $\mathrm{MPTP}^{a}$ & DRT-off $^{b}$ & DRT-on $^{c}$ \\
\hline $\begin{array}{l}\text { A. Firing rates (spikes/sec), } \\
\text { mean } \pm \mathrm{SEM}^{d}\end{array}$ & $\begin{array}{l}\text { GPe } \\
\text { GPi }\end{array}$ & $\begin{array}{l}57.1 \pm 2.1(n=96) \\
62.9 \pm 3.3(n=22)\end{array}$ & $\begin{array}{l}45.4 \pm 1.7(n=92)^{*} \\
75.3 \pm 4.5(n=37)\end{array}$ & $\begin{array}{l}30.3 \pm 1.9(n=89)^{*} \\
69.5 \pm 5.9(n=17)\end{array}$ & $\begin{array}{l}80.3 \pm 3.8(n=51)^{*, * *} \\
29.1 \pm 4.7(n=30)^{*, * *}\end{array}$ \\
\hline $\begin{array}{l}\text { B. Percentage of correlated } \\
\text { neuronal pairs }\end{array}$ & $\begin{array}{l}\mathrm{GP}_{\text {all }^{-}-\mathrm{GP}_{\text {all }} f} \\
\text { GPe-GPe } \\
\text { GPi-GPi }\end{array}$ & $\begin{array}{l}16.7 \%(100 / 599) \\
26.3 \%(26 / 99) \\
20.0 \%(9 / 45)\end{array}$ & $\begin{array}{l}46.9 \%(399 / 851)^{*} \\
41.9 \%(26 / 62) \\
82.1 \%(55 / 67)^{*}\end{array}$ & $\begin{array}{l}71.4 \%(359 / 503)^{*} \\
78.8 \%(93 / 118)^{*} \\
80.0 \%(8 / 10)^{*}\end{array}$ & $\begin{array}{l}25.0 \%(94 / 376)^{* *} \\
32.6 \%(14 / 43)^{* *} \\
57.1 \%(12 / 21)\end{array}$ \\
\hline $\begin{array}{l}\text { C. Percentage of oscillatory out } \\
\text { of all non-flat correlograms }\end{array}$ & $\begin{array}{l}\mathrm{GP}_{\mathrm{all}^{-}-\mathrm{GP}_{\text {all }}{ }^{f}} \\
\text { GPe-GPe } \\
\text { GPi-GPi }\end{array}$ & $\begin{array}{l}4.0 \%(4 / 100) \\
15.4 \%(4 / 26) \\
0 \%(0 / 9)\end{array}$ & $\begin{array}{l}67.7 \%(270 / 399)^{*} \\
38.5 \%(10 / 26) \\
94.5 \%(52 / 55)^{*}\end{array}$ & $\begin{array}{l}43.7 \%(157 / 359)^{*} \\
45.2 \%(42 / 93) \\
87.5 \%(7 / 8)^{*}\end{array}$ & $\begin{array}{l}42.6 \%(40 / 94)^{*} \\
35.7 \%(5 / 14) \\
83.3 \%(10 / 12)^{*}\end{array}$ \\
\hline
\end{tabular}

${ }^{a}$ MPTP corresponds to MPTP-treated L-DOPA-naive parkinsonian monkey.

${ }^{b}$ DRT-off corresponds to off periods (before morning dose) of MPTP monkey undergoing daily DRT.

${ }^{c}$ DRT-on corresponds to on periods of MPTP monkey after DRT.

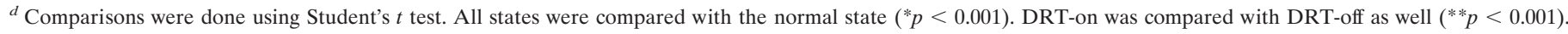

${ }^{e}$ Comparisons were done using $\chi^{2}$ test. All states were compared with the normal state $\left({ }^{*} p<0.001\right)$. DRT-on was compared with DRT-off as well $(* * p<0.001)$.

${ }^{f} \mathrm{GP}_{\text {all }}-\mathrm{GP}_{\text {all }}$-all combinations of GPe, GPi, and GP neuronal pairs.

after MPTP treatment. This increase in correlation was augmented in the DRT-off periods and reversed to near normal levels in the on periods (Table $1 B$, Fig. $1 B$ ). The pattern of correlation also varied between the states, with a notable increase in proportion of oscillatory correlograms after MPTP. However, the fraction of oscillatory correlated pairs did not return to normal values during on periods (Table $1 C$ ). The ratio of positive (peaks) to negative (troughs) nonflat cross-correlograms (Fig. 3E) ranged from 2.2 to 3.5 throughout all clinical states.

Separate analysis of $\mathrm{GP}_{\mathrm{e}}$ pairs and $\mathrm{GP}_{\mathrm{i}}$ pairs revealed differences in correlation level and pattern in the two nuclei (Table $1 B, C)$. In the $\mathrm{GP}_{\mathrm{i}}$, there was a vast increase in percentage of correlated pairs in the MPTP compared with the normal state but no further change in the percentage of correlated pairs in the DRT-off periods. In the $\mathrm{GP}_{\mathrm{e}}$, however, the increase in the per-
A

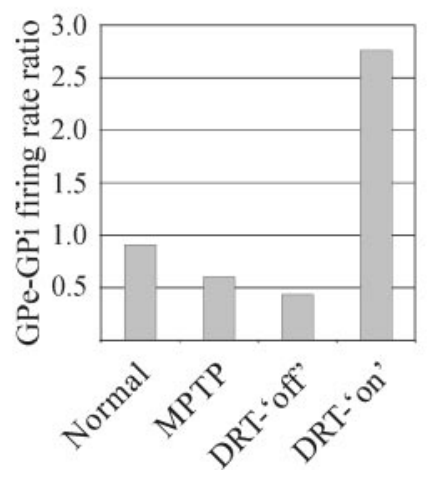

B

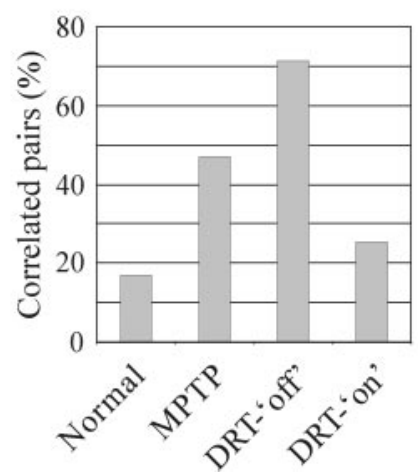

Figure 1. Summary of changes in firing rates and correlation in each clinical state. $A$, Changes in neuronal firing rates in the $\mathrm{GP}_{\mathrm{e}}$ and $\mathrm{GP}_{\mathrm{i}}$ proceed in opposite directions in response to dopamine depletion and replacement. After induction of parkinsonism, neuronal firing rates decrease in the $\mathrm{GP}_{\mathrm{e}}$ and increase in the $\mathrm{GP}_{\mathrm{i}}$, and the reverse occurs in response to DRT. The $y$-axis is the ratio between mean firing rates of $\mathrm{GP}_{\mathrm{e}}$ and $\mathrm{GP}_{\mathrm{i}}$ neurons. MPTP, MPTP-treated L-DOPA-naive parkinsonian monkey; DRT-off, off periods (before morning dose) of MPTP monkey undergoing daily DRT; DRT-on, on periods of MPTP monkey after DRT. $B$, Neuronal synchronization increases after dopamine depletion and decreases in response to dopamine replacement. Neurons from both pallidal segments are pooled. The $y$-axis is the percentage of correlated pairs. Clinical state definitions are the same as in $A$. centage of correlated pairs in the MPTP state compared with the normal state was moderate, with a greater increase in synchronization in the DRT-off periods. The decrease in percentage of correlated pairs in DRT-on periods was noted both among GP pairs and $\mathrm{GP}_{\mathrm{i}}$ pairs (Table $1 B$ ). In addition, although the vast majority of correlated $\mathrm{GP}_{\mathrm{i}}$ pairs were oscillatory, a significant portion of the correlated $\mathrm{GP}_{\mathrm{e}}$ pairs exhibited nonoscillatory correlation (Table $1 C$ ).

Stable recordings of 94 pallidal pairs (42 cells, 8 recording days) were maintained during and after the off-on transition. Analysis of correlation in these pairs showed a similar reversal of abnormal correlation from $77.7 \%$ correlated pairs in the off period to $26.6 \%$ in the on period ( $p<0.001, \chi^{2}$ test). An origin-based subclassification of the 94 pairs showed that of the $62 \mathrm{GP}_{\mathrm{e}}-\mathrm{GP}_{\mathrm{e}}$ and
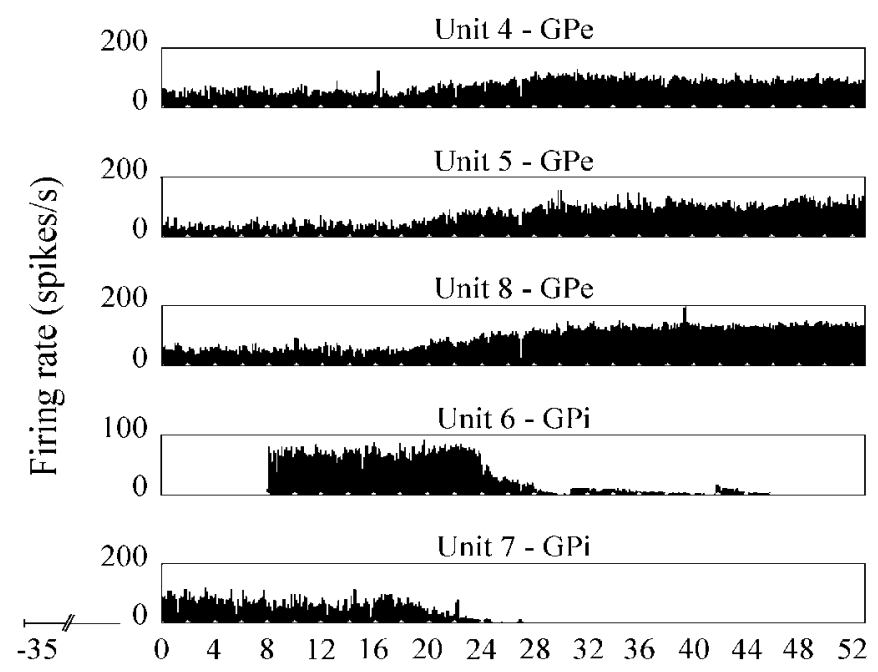

1 DRT medication $\Uparrow$ Beginning of 'on'

Time (min)

Figure 2. Discharge rates of five continuously recorded pallidal neurons during the clinical off-on transition, demonstrating an increase in discharge rate of $\mathrm{GP}_{\mathrm{e}}$ units and a decrease in $\mathrm{GP}_{\mathrm{i}}$ units. DRT was administered orally $35 \mathrm{~min}$ before onset of recording (solid arrow); clinical off-on transition began after 14 min of recording (open arrow). All units were recorded continuously through minutes $0-52$, except for unit 6 , which was recorded through minutes $8-46$. The $x$-axis is time in minutes; $y$-axis is the firing rate of each unit in spikes/sec. 
A

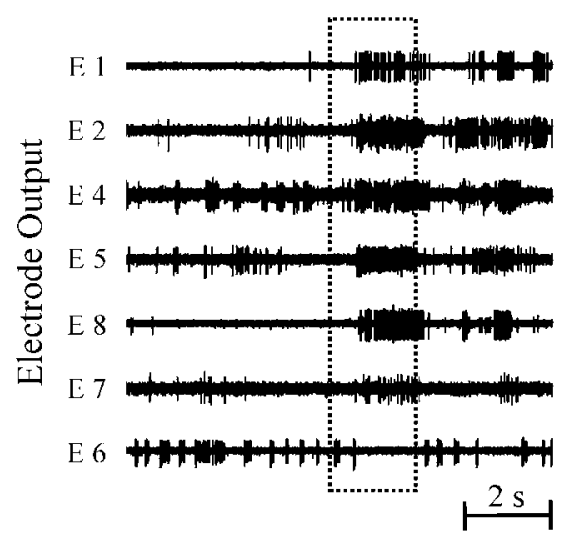

B

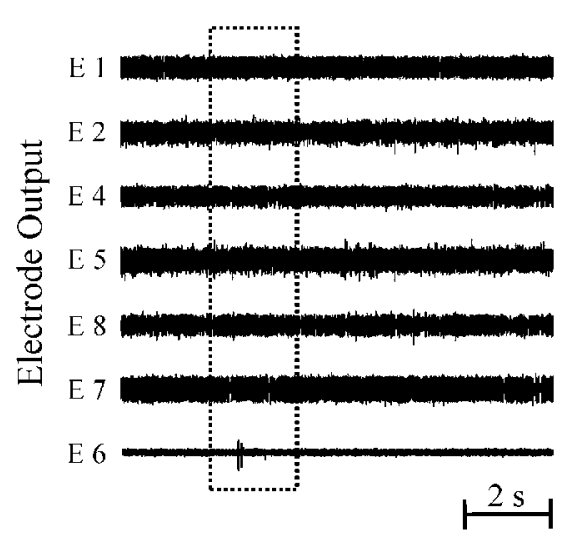

C

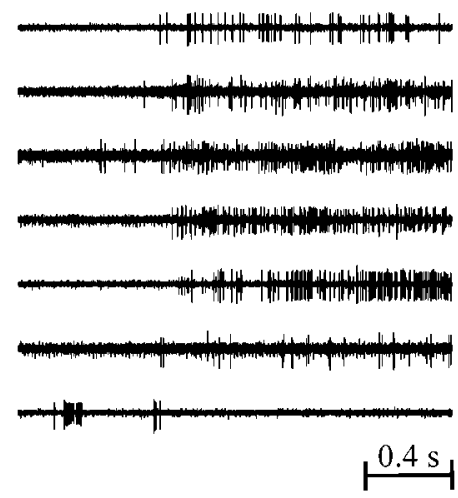

D

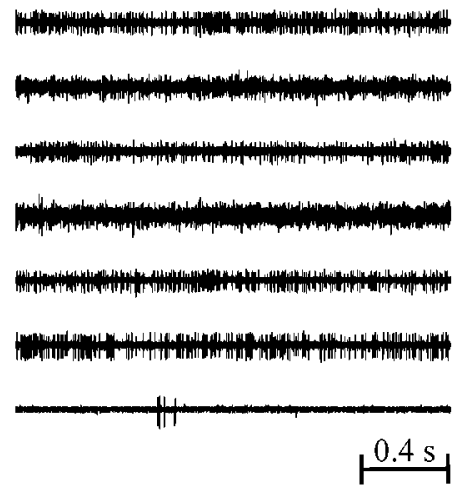

E

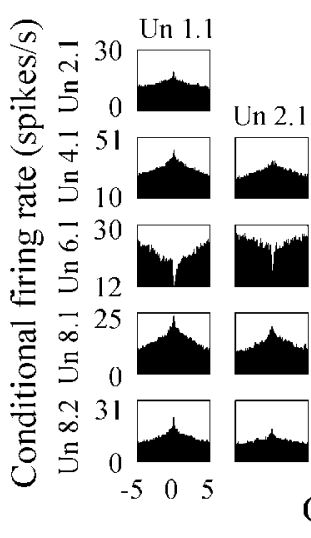

Un 2.1 - Un 4.1

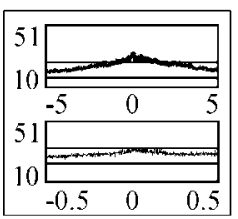

Un 4.
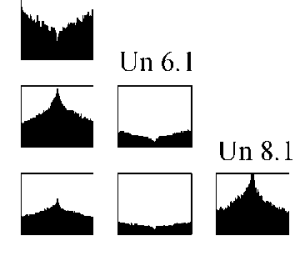

Offset (s)

Figure 3. Examples of changes in neuronal synchronization in response to DRT. $A, B$, Simultaneous recording from the GP of the MPTP monkey undergoing daily DRT in off period $(A)$ and the same cells in on period 26 min later $(B)$. The recordings show synchronized bursts in the off period but not in the on period. The $x$-axis is time in seconds. $C, D$, Temporal magnification of 2 sec from the traces shown in $A$ and $B$, respectively. $E$, $F$, Cross-correlogram matrices of the units shown in $A$ and $B$, demonstrating long-range cross-correlations in the off period $(E)$ that are flattened in the on period $(F)$. The $x$-axis is the offset of the cross-correlogram in seconds; $y$-axis is the conditional firing rate in spikes/sec. Un $x, y$ corresponds to unit number $y$ in electrode number $x$. E, Inset, Demonstrates how the cross-correlogram of units 2.1 and 4.1 crosses confidence lines when calculated for \pm 5 sec offset and does not cross the confidence lines when calculated for $\pm 0.5 \mathrm{sec}$ offset. $x$ - and $y$-axes are the same as for $E$ and $F$.

$\mathrm{GP}_{\mathrm{e}}-\mathrm{GP}$ pairs, $47(75.8 \%)$ were correlated before medication and only $22(35.5 \%)$ were correlated after DRT. Among the six $\mathrm{GP}_{\mathrm{i}}-\mathrm{GP}_{\mathrm{i}}$ and $\mathrm{GP}_{\mathrm{i}}-\mathrm{GP}$ pairs, five $(83.3 \%)$ were correlated before medication and none after. A similar reduction in correlation was observed among the seven $\mathrm{GP}_{\mathrm{e}}-\mathrm{GP}_{\mathrm{i}}$ pairs, from six correlated pairs before DRT to none after. Examples of typical crosscorrelation matrices in consecutive off and on periods are shown in Figure 3, $E$ and $F$.

\section{DISCUSSION}

In this study, we used simultaneous multiple electrode recording to calculate the neuronal correlation during DRT of an MPTP monkey. In contrast to the ultrafast intramuscular apomorphine used in most previous studies, we used the customary oral medications (L-DOPA combined with a postsynaptic dopamine agonist) administered in clinical practice. In addition, the continuous recording of many cells before, during, and after the clinical off-on transition served to avoid potential selection bias of cells in two different clinical states. Our main findings are that (1) dopamine depletion decreases the neuronal firing rates in $\mathrm{GP}_{\mathrm{e}}$ and increases the neuronal firing rates in $\mathrm{GP}_{\mathrm{i}},(2)$ dopamine depletion increases neuronal synchronization in both pallidal segments, and (3) DRT reverses all of the above changes.

\section{Clinical effects of MPTP and DRT}

The monkey developed the full clinical spectrum of MPTPinduced parkinsonism (Burns et al., 1983; Bergman et al., 1994). The responses of the monkey to DRT resembled the common effects (both therapeutic and adverse) seen in human patients. As in other primate studies (Bedard et al., 1986; Pearce et al., 1995), the doses required (in milligrams per kilogram) to achieve the optimal therapeutic response were higher than the doses used in most human patients. This could be a result of either the acute effect of MPTP (achieving a state of severe parkinsonism within a few days) or species differences, such as the higher metabolic rate of $3 \mathrm{~kg}$ monkeys, differences in gut absorption, activities of metabolic enzymes, and penetration of the blood-brain barrier. The appearance of dyskinesia in the monkey after only a few weeks of DRT compared with several years in parkinsonian patients has also been reported (Bedard et al., 1986; Pearce et al., 1995) and can be attributed to the same factors.

Because changes in both discharge rates and correlation ap- 
peared to proceed in the same direction in the optimal DRT state and after the development of dyskinesia, we considered the two states together in the present analysis. The higher number of observations in the grouped data serves better for the purpose of comparing the dopamine-depleted animal with the animal with DRT. The differences between optimal and dyskinetic DRT should be further investigated in future studies.

\section{Changes in firing rates}

The classic model of the basal ganglia (Albin et al., 1989; DeLong, 1990) predicts that striatal dopamine depletion will result in overactivity of $\mathrm{GP}_{\mathrm{i}}$ neurons and reduced activity of $\mathrm{GP}_{\mathrm{e}}$ neurons. Early MPTP primate electrophysiological studies have verified the predictions of the model in the dopamine-depleted state (Miller and DeLong, 1987; Filion and Tremblay, 1991). However, these observations have not been fully confirmed by recent studies (Boraud et al., 1998; Wichmann et al., 1999; Raz et al., 2000).

In the same manner, the prediction of the model that DRT will cause a reversal of pallidal rate changes has been verified by some but not all studies. Apomorphine injections have been reported to result in increased $\mathrm{GP}_{\mathrm{e}}$ activity and reduced $\mathrm{GP}_{\mathrm{i}}$ activity (Filion et al., 1991; Hutchinson et al., 1997). Other primate (Papa et al., 1999) and human (Levy et al., 2001) studies restricted to $\mathrm{GP}_{\mathrm{i}}$ neurons alone have confirmed the predicted decrease in $\mathrm{GP}_{\mathrm{i}}$ neuronal firing rate. However, a third study examining the effect of chronic L-DOPA treatment in MPTP monkeys demonstrated a significant decrease in $\mathrm{GP}_{\mathrm{i}}$ firing rates but did not find a significant increase in $\mathrm{GP}_{\mathrm{e}}$ firing rates in response to DRT (Boraud et al., 1998). Similarly, metabolic studies of animal models of parkinsonism challenge the prediction of decreased striatal inhibition of $\mathrm{GP}_{\mathrm{e}}$ after DRT (Mitchell et al., 1992; Herrero et al., 1996; Vila et al., 1997).

Our study verified the predicted rate changes in both segments of the pallidum in the dopamine-depleted and the dopaminereplacement state (Fig. $1 A$, Table $1 A$ ). The conflicting earlier results, especially regarding $\mathrm{GP}_{\mathrm{e}}$ activity, might be caused by differences in recording techniques or individual responses to MPTP. Moreover, metabolic studies could be influenced by other factors (such as firing pattern and synchronization) in addition to firing rates.

The overshooting of the firing rates beyond normal values in both pallidal segments during DRT-on periods, as well as total firing cessation of some $\mathrm{GP}_{\mathrm{i}}$ cells, has been described before (Papa et al., 1999; Obeso et al., 2000). We ascribe this overshooting to the unregulated manner (temporally and spatially) in which dopamine is introduced to the circuitry during DRT. We further believe that these rate disturbances might serve as part of the neuronal substrate of L-DOPA-induced dyskinesia.

\section{Changes in synchronization}

Previous primate (Nini et al., 1995; Raz et al., 2000) and human (Hurtado et al., 1999; Levy et al., 2000) studies have shown an increase in neuronal synchronization in the basal ganglia of parkinsonian subjects. Our results confirm the increase in neuronal synchronization after induction of parkinsonism and show that this increased level of synchronization is maintained in the off periods of chronic DRT and reversed during DRT-on periods. The co-occurrence of the decrease in synchronization with clinical improvement supports the notion that abnormal synchronization plays a key role in the pathophysiology of parkinsonism. However, current methods fall short in evaluating the precise temporal relationships between the clinical and neuronal changes
(Ben Shaul et al., 2001), and future studies on this subject are necessary.

The relatively higher proportion of correlated pairs that we found in the normal state compared with previous works (Nini et al., 1995; Raz et al., 2000) might result from slow mutual processes (Walters et al., 2000; Wichmann et al., 2002) that could not be revealed by short-time-scale cross-correlograms. Indeed, when checking our data in the normal state for significant correlations using the previously applied calculation of $\pm 500 \mathrm{msec}$ offset correlograms, we found only $7.5 \%$ (45 of 599) correlated pairs (Fig. $3 E$, inset). These results are not significantly different from previous reports and corroborate our claim that using a longer offset in the correlogram calculation results in a higher detection rate of correlation.

Changes in correlated activity in the various states of dopamine depletion and replacement differed for the two segments of the pallidum. Whereas in the $\mathrm{GP}_{\mathrm{i}}$, correlation was greatly increased after induction of parkinsonism but did not change thereafter during the DRT-off state, in the $\mathrm{GP}_{\mathrm{e}}$, there was a significant additional increase in correlation in the DRT-off state. This, along with a similar additional decrease in the $\mathrm{GP}_{\mathrm{e}}$ discharge rates during DRT-off, with no corresponding change in the $\mathrm{GP}_{\mathrm{i}}$, might imply that the chronic effect of DRT is more prominent in the external pallidum. Such chronic effects of DRT on circuitry and neural properties could also play a role in the generation of L-DOPA-induced dyskinesia. The similarity between the percentage of correlated pairs in the total pallidal population and the percentage of correlated pairs within the $\mathrm{GP}_{\mathrm{e}}$ is probably related to the predominance of $\mathrm{GP}_{\mathrm{e}}$ neurons among the nonclassified GP neurons in our database.

The fact that the firing rate changes in response to DRT shift in opposite directions in $\mathrm{GP}_{\mathrm{e}}$ and $\mathrm{GP}_{\mathrm{i}}$ implies that the accompanying changes in correlation are not a byproduct of discharge rate changes. In contrast to previous primate and human reports (Raz et al., 2000; Levy et al., 2002), we found that a significant portion of correlated activity was nonoscillatory and wide-ranged (Table $1 C$, Fig. $3 A, E$ ). This discrepancy can be explained by the wider time scale used in the present study and provides strong evidence that abnormal pallidal synchronization is not a mere byproduct of the appearance of oscillations in the circuitry.

We conclude that abnormal neuronal synchronization in output nuclei of the basal ganglia is correlated with the clinical signs of parkinsonism and that the desynchronization of pallidal output might be a key factor in therapeutic manipulations of Parkinson's disease such as DRT and deep brain surgeries.

\section{REFERENCES}

Albin RL, Young AB, Penney JB (1989) The functional anatomy of basal ganglia disorders. Trends Neurosci 12:366-375.

Bar-Gad I, Ritov Y, Bergman H (2001) Failure in identification of overlapping spikes from multiple neuron activity causes artificial correlations. J Neurosci Methods 107:1-13.

Bedard PJ, Di Paolo T, Falardeau P, Boucher R (1986) Chronic treatment with L-DOPA, but not bromocriptine induces dyskinesia in MPTP-parkinsonian monkeys: correlation with [3H]spiperone binding. Brain Res 379:294-299.

Ben Shaul Y, Bergman H, Ritov Y, Abeles M (2001) Trial to trial variability in either stimulus or action causes apparent correlation and synchrony in neuronal activity. J Neurosci Methods 111:99-110.

Bergman H, Wichmann T, Karmon B, DeLong MR (1994) The primate subthalamic nucleus. II. Neuronal activity in the MPTP model of parkinsonism. J Neurophysiol 72:507-520.

Boraud T, Bezard E, Guehl D, Bioulac B, Gross C (1998) Effects of L-DOPA on neuronal activity of the globus pallidus externalis $\left(\mathrm{GP}_{\mathrm{e}}\right)$ and globus pallidus internalis $\left(\mathrm{GP}_{\mathrm{i}}\right)$ in the MPTP-treated monkey. Brain Res 787:157-160.

Burns RS, Chiueh CC, Markey SP, Ebert MH, Jacobowitz DM, Kopin IJ 
(1983) A primate model of parkinsonism: selective destruction of dopaminergic neurons in the pars compacta of the substantia nigra by $N$-methyl-4-phenyl-1,2,3,6-tetrahydropyridine. Proc Natl Acad Sci USA 80:4546-4550.

Contreras CM, Mexicano G, Guzman-Flores CA (1981) Stereotaxic brain atlas of the green monkey (Cercopithecus aethiops aethiops). Bol Estud Med Biol 31:383-428.

DeLong MR (1990) Primate models of movement disorders of basal ganglia origin. Trends Neurosci 13:281-285.

Filion M, Tremblay L (1991) Abnormal spontaneous activity of globus pallidus neurons in monkeys with MPTP-induced parkinsonism. Brain Res 547:142-151.

Filion M, Tremblay L, Bedard PJ (1991) Effects of dopamine agonists on the spontaneous activity of globus pallidus neurons in monkeys with MPTP-induced parkinsonism. Brain Res 547:152-161.

Herrero MT, Levy R, Ruberg M, Luquin MR, Villares J, Guillen J, Faucheux B, Javoy Agid F, Guridi J, Agid Y, Obeso JA, Hirsch EC (1996) Consequence of nigrostriatal denervation and L-dopa therapy on the expression of glutamic acid decarboxylase messenger RNA in the pallidum. Neurology 47:219-224.

Hurtado JM, Gray CM, Tamas LB, Sigvardt KA (1999) Dynamics of tremor-related oscillations in the human globus pallidus: a single case study. Proc Natl Acad Sci USA 96:1674-1679.

Hutchison WD, Lozano AM, Davis KD, Saint Cyr JA, Lang AE, Dostrovsky JO (1994) Differential neuronal activity in segments of globus pallidus in Parkinson's disease patients. NeuroReport 5:1533-1537.

Hutchinson WD, Levy R, Dostrovsky JO, Lozano AM, Lang AE (1997) Effects of apomorphine on globus pallidus neurons in parkinsonian patients. Ann Neurol 42:767-775.

Imbert C, Bezard E, Guitraud S, Boraud T, Gross CE (2000) Comparison of eight clinical rating scales used for the assessment of MPTPinduced parkinsonism in the macaque monkey. J Neurosci Methods 96:71-76.

Levy R, Hutchison WD, Lozano AM, Dostrovsky JO (2000) Highfrequency synchronization of neuronal activity in the subthalamic nucleus of parkinsonian patients with limb tremor. J Neurosci 20:7766-7775.

Levy R, Dostrovsky JO, Lang AE, Sime E, Hutchison WD, Lozano AM (2001) Effects of apomorphine on subthalamic nucleus and globus pallidus internus neurons in patients with Parkinson's disease. J Neurophysiol 86:249-260.

Levy R, Hutchison WD, Lozano AM, Dostrovsky JO (2002) Synchronized neuronal discharge in the basal ganglia of parkinsonian patients is limited to oscillatory activity. J Neurosci 22:2855-2861.

Merello M, Balej J, Delfino M, Cammarota A, Betti O, Leiguarda R
(1999) Apomorphine induces changes in GP $\mathrm{P}_{\mathrm{i}}$ spontaneous outflow in patients with Parkinson's disease. Mov Disord 14:45-49.

Miller WC, DeLong MR (1987) Altered tonic activity of neurons in the globus pallidus and subthalamic nucleus in the primate MPTP model of parkinsonism. In: The basal ganglia II (Carpenter MB, Jayaraman A, eds), pp 415-427. New York: Plenum.

Mitchell IJ, Boyce S, Sambrook MA, Crossman AR (1992) A 2-deoxyglucose study of the effects of dopamine agonists on the parkinsonian primate brain: implications for the neural mechanisms that mediate dopamine agonist-induced dyskinesia. Brain 115:809-824.

Nini A, Feingold A, Slovin H, Bergman H (1995) Neurons in the globus pallidus do not show correlated activity in the normal monkey, but phase-locked oscillations appear in the MPTP model of parkinsonism. J Neurophysiol 74:1800-1805.

Obeso JA, Rodriguez-Oroz MC, Rodriguez M, Lanciego JL, Artieda J, Gonzalo N, Olanow CW (2000) Pathophysiology of the basal ganglia in Parkinson's disease. Trends Neurosci 23:S8-S19.

Papa SM, DeSimone R, Fiorani M, Oldfield EH (1999) Internal globus pallidus discharge is nearly suppressed during levodopa-induced dyskinesias. Ann Neurol 46:732-738.

Pearce RK, Jackson M, Smith L, Jenner P, Marsden CD (1995) Chronic L-DOPA administration induces dyskinesias in the 1-methyl-4-phenyl1,2,3,6-tetrahydropyridine-treated common marmoset (Callithrix jacchus). Mov Disord 10:731-740.

Raz A, Vaadia E, Bergman H (2000) Firing patterns and correlations of spontaneous discharge of pallidal neurons in the normal and the tremulous 1-methyl-4-phenyl-1,2,3,6-tetrahydropyridine vervet model of parkinsonism. J Neurosci 20:8559-8571.

Vidailhet M, Bonnet AM, Marconi R, Durif F, Agid Y (1999) The phenomenology of L-dopa-induced dyskinesias in Parkinson's disease. Mov Disord 14 [Suppl 1]:13-18.

Vila M, Levy R, Herrero MT, Ruberg M, Faucheux B, Obeso JA, Agid Y, Hirsch EC (1997) Consequences of nigrostriatal denervation on the functioning of the basal ganglia in human and nonhuman primates: an in situ hybridization study of cytochrome oxidase subunit I mRNA. J Neurosci 17:765-773.

Walters JR, Ruskin DN, Allers KA, Bergstrom DA (2000) Pre- and postsynaptic aspects of dopamine-mediated transmission. Trends Neurosci 23:S41-S47.

Wichmann T, Bergman H, Starr PA, Subramanian T, Watts RL, DeLong MR (1999) Comparison of MPTP-induced changes in spontaneous neuronal discharge in the internal pallidal segment and in the substantia nigra pars reticulata in primates. Exp Brain Res 125:397-409.

Wichmann T, Kliem MA, Soares JC (2002) Slow oscillatory discharge in the primate basal ganglia. J Neurophysiol 87:1145-1148. 